\title{
COMUNICAÇÃO
}

\section{HEPATITE DE LÁBREA: UM QUADRO HISTOLÓGICO CARACTERÍSTICO?}

\section{Zilton A. Andrade}

A hepatite de Lábrea, febre de Lábrea, ou febre negra, é uma doença aguda grave que se manifesta por agitação psicomotora, com a elevada mortalidade, ocorrendo preferencialmente na região amazônica ${ }^{9}{ }^{17}$, Sua etiologia é desconhecida. As possibilidades têm variado entre uma etiologia tóxica ou infecciosa e, mais recentemente, como dependente da interaçào entre o virus B da hepatite e o agente Delta. Embora tenha havido a demonstração do agente Delta em alguns casos de hepatite de Lábrea 158 , inclusive em 4 dos 7 casos que tivemos a oportunidade de estudar, esta etiologia fica improvável pela alta prevalência de hepatite $B$ e agente Delta na regiāo amazônica ${ }^{4}$, enquanto a hepatite de Lábrea é mais rara, porque há um quadro clínico patológico hepático bem diferente observado no resto do mundo na presença de tal infecção 106 e porque há casos de hepatite de Lábrea negativos para agente Delta. Também o quadro da infecção experimental é diferente ${ }^{16}$.

Os dados clinico-epidemiológicos têm sido muito valorizados para se definir a existencia da hepatite de Lábrea como uma entidade autônoma. O surgimento em microepidemias, o envolvimento predominante de crianças, a agitação psicomotora. o vômito negro e a localização dos casos em áreas da região amazônica são os elementos principais ${ }^{17}$. Estes dados são realmente muito importantes, embora um quadro histopatológico da hepatite de Lábrea tenha sido detectado em dois casos brasileiros, no Rio de Janeiro $^{14}$ e Bahia ${ }^{1}$.

Todavia o argumento poderoso a favor da existência da hepatite de Lábrea como uma entidade autônoma é o seu quadro histopatológico. Todos os patologistas que têm tido a oportunidade de estudar a doença têm ficado impressionados com o quadro histopatológico hepático considerado como caracteristico ou patognomônico. O elemento mais proeminente deste quadro é representado por uma microvacuolização e tumefação dos hepatócitos, com acúmulo de gordura e sem deslocamento do núcleo para a periferia da célula, a chamada "célula em mórula" ou "em aranha". Esta alteraçăo da degeneração gorda aguda tem sido identificada como resultante de um distúrbio na excreção de lipo-proteinas de baixa densidade ${ }^{12}$ e nada tem de patognomônico. Aparece no figado gordo agudo da gravidez ${ }^{5}$, no envenenamento pela tetraciclinal ${ }^{1}$, na hepatite tóxica após administração de hycanthone ${ }^{2}$, etc. É todavia bem diferente da microvesiculação do hepatócito, geralmente sem tumefação, que ocorre na sindrome de Reye ${ }^{13}$.

Vários autores têm se referido à presença de necrose litica e coagulativa, além das células em mórula, o que contribui para tornar o quadro mais característico $^{37}$. Todavia na hepatite tóxica pós Hycanthone ${ }^{2}$ e na doença de Wilson aguda ${ }^{18}$ ocorrem numerosas células em mórula ao lado de necrose lítica e coagulativa. No entanto, nas duas condições acima, a necrose hepatocelular é seguida de colapso da trama reticular, com a conseqüente formação de septos e o surgimento de regeneração nodular do parênquima.

$\mathrm{Na}$ hepatite de Lábrea os focos de necroses são numerosos e disseminados, mas são relativamente pequenos dentro do lóbulo hepático e não induzem ao colapso da trama (Fig. 1). Quando muito pode haver a aproximação dos feixes reticulares (Fig. 2), principalmente nas zonas periportais, mas não o colapso completo. Enfim, não há necrose maciça ou submaciça, mas apenas necrose multifocal. Este detalhe é que torna o quadro histopatológico da hepatite de Lábrea altamente característico, senão mesmo patognomônico.

Esta comunicação se constitui numa tentativa para se definir a especificidade do quadro histopatológico da hepatite de Lábrea: uma lesão com degeneração gordurosa aguda dos hepatócitos ("células em mórula") acompanhada de proeminente necrose multifocal, lítica e coagulativa, sem colapso da trama reticular, e com variável componente de inflamação mononuclear acompanhado de proliferação dos canaliculos biliares na dependència do tempo de sobrevida do paciente. 
Comunicą̧ào. Andrade ZA. Hepatite de Lábrea: um quadro histológico caracteristico? Revista da Sociedade Brasileira de Medicina Tropical 19:263-265. Out Dez, 1986.

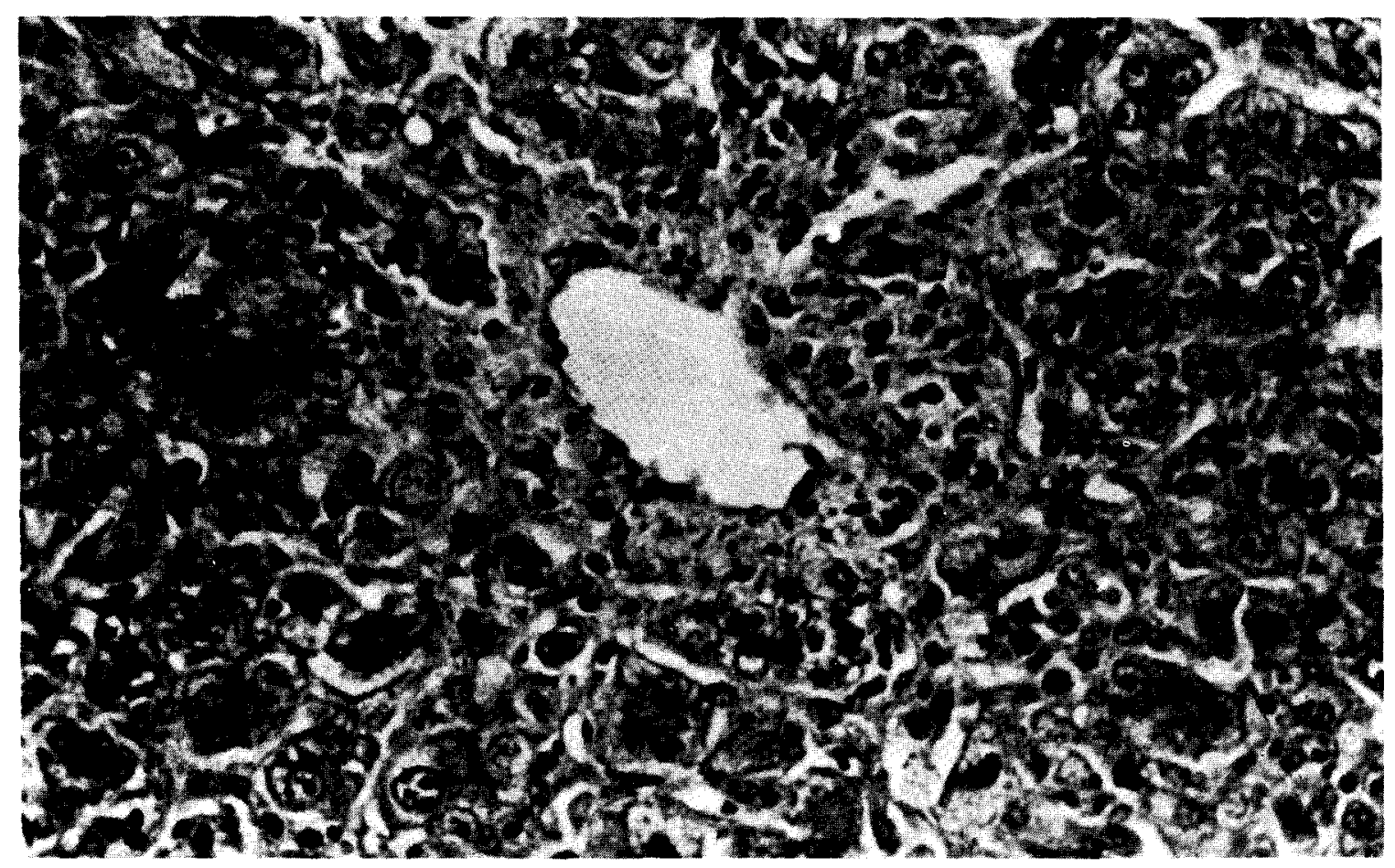

Fig. 1 - Hepatite de Lábrea em criança com 4 anos de idade. Há desaparecimento de hepatócitos (necrose litica) em torno de uma veia central e em focos isolados no parênquima, além de discreta infiltraçào de células mononucleares e de algumas "células em mórula".

Hematoxilina e eosina $X 300$.

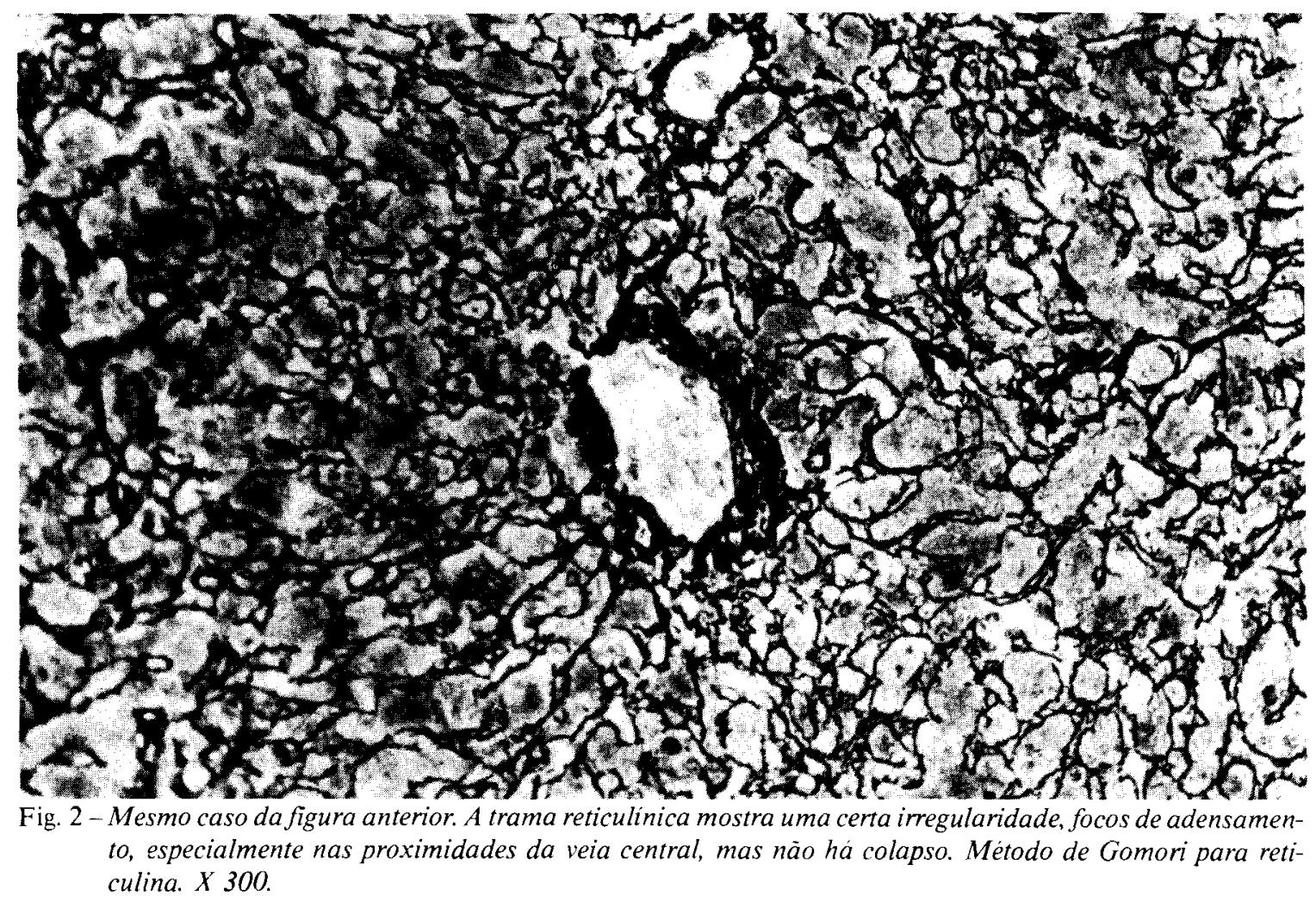




\section{REFERÊNCIAS BIBLIOGRÁFICAS}

1. Andrade ZA. Barbosa Jr AA. Hepatite de Labrea em Salvador, BA? (Apresentação de um possivel caso). Memórias do Instituto Oswaldo Cruz 78:491-496, 1983.

2. Andrade ZA. Santos HA, Borojevic R, Grimaud JA. Lesões hepáticas produzidas por Hycanthone (Etrenol). Revista do Instituto de Medicina Tropical de São Paulo 16:160-170, 1974.

3. Andrade ZA. Santos JB, Prata A, Dourado H. Histopatologia da hepatite de Lábrea. Revista da Sociedade Brasileira de Medicina Tropical 16:31-40, 1983.

4. Bensabath $G$. Hepatite de Lábrea (febre negra de Lábrea) e outras hepatites fulminantes em Sena Madureira, Acre e Boca do Acre, Amazonas, Brasil. Revista do Instituto de Medicina Tropical de São Paulo 25:182194, 1983 .

5. Breen KJ, Perkins KW, Mistilis SP, Sherman R. Idiopathic acute fatty liver of pregnancy. Gut 11:822-825. 1970.

6. Colombo M, Cambieri R. Rumi MG, Ronchi G, Del Ninno E, de Francis R. Long-term delta superinfection in $\mathrm{HBsAg}$ carriers and its relationship to the course of chronic hepatitis. Gastroenterology 85:235-239, 1983.

7. Dias LB, Coura JR. Hepatite de Lábrea. Estudo de revisão em viscerotomias hepáticas dos anos 1934 a 1940. Revista do Instituto de Medicina Tropical de São Paulo 27:242-248, 1985.

8. Fonseca JCF. Gayotto JCC, Ferreira LC L, Araujo JR. Alecrim WD, Santos RTM, Simonetti JP. Alves VAF. Labrea Hepatitis - hepatitis B and Delta antigen expression in liver tissue: report of three autopsy cases. (Preliminary report). Revista do Instituto de Medicina Tropical de São Paulo 27:224-227. 1985.

9. Gast-Galvis A. Viscerotomia en Colombia. Resultado del examen histo-patológico de 22.000 muestras de higado humano. Revista Médica (Bogotá) 553:1-34. 1975.

10. Govindarajan S, Chin KP, Redeker AG, Peters RL. Fulminant B viral hepatitis: role of Delta agent. Gas troenterology 86: 1417-1420, 1984.

11. Hansen CH, Pearson LH. Schencker S, Combes B. Impaired secretion of triglycerides by the liver; a cause of tetracycline - induced fatty liver. Proceedings of the Society of Experimental Biology and Medicine 128: 143-146, 1968.

12. Maddrey WC, Boitnott JK. Drug induced chronic hepatitis and cirrhosis. In: Popper H. Schaffner F. (ed) Progress in Liver Diseases. Vol 6, Grune \& Stratton. Neu York, p. 595-603, 1979.

13. Moren OM, Barbosa H. Pratesi R, Alves da Mata V, Souza MOA. Sindrome de Reye. Estudo de 18 casos em Brasilia. D.F. Jornal de Pediatria 39:217-221, 1974.

14. Paiva LM, Kazen J, Miyaqui T, Barreto Netto $\mathbf{M}$. Esteatose microvesicular como substrato de hepatite aguda grave. Provável relaçào com hepatite de Labrea. Arquivos Brasileiros de Medicina 57:71-74, 1983.

15. Popper H. Thung SN. Gerber MA. Hadler SC. Monzon M, Ponzetto A. Anzola E, Rivera D, Mondolfi A, Bracho A, Francis DP. Gerin JL, Maynard JL, Purcell RH. Histologic studies of severe Delta infection in Venezuelan indians. Hepatology 3:906-912. 1983.

16. Rizzetto M. Canese MG, Gerin JL, London WT. Sly DL, Purcell RH. Transmission of the hepatitis B virus associated Delta antigen to chimpanzees. Joumal of Infectious Diseases 141:590-602, 1980

17. Santos JB. Febre negra na região de Lábrea, Amazonas. Estudo clinico, epidemiológico e histopatologico. Tese de Mestrado. Universidade de Brasília, DF. 1978.

18. Vargas M. Enfermedad de Wilson fulminante. II Simposio Hispano-parlante de Hepatologia. Cocoyoc, Mexico, 1985. 